\title{
JURNAL HARIAN/MINGGUAN
}

\begin{tabular}{|c|c|c|c|c|c|c|c|}
\hline \multicolumn{2}{|c|}{$\begin{array}{l}\text { Nama Mahasiswa } \\
\text { No. STB/NIRM } \\
\text { Desa / Posko } \\
\text { Kecamatan } \\
\text { Kabupaen }\end{array}$} & $\begin{array}{l}\text { : MUH. IS } \\
\text { : } 1918377 \\
\text { : Balang B } \\
\text { : Tarowan } \\
\text { : Jenepont }\end{array}$ & $\begin{array}{l}\text { VAHYUDI SE } \\
+10351 \\
\mathrm{ru}\end{array}$ & AWAN & & & \\
\hline No & $\begin{array}{c}\text { Minggu } \\
\text { ke- }\end{array}$ & Hari / Tgl & Jam & Jenis Kegiatan & Lokasi & Yang Terlibat & Hasil \\
\hline \multirow[t]{2}{*}{1} & \multirow[t]{14}{*}{$\begin{array}{c}\text { IV } \\
\text { (keempat) }\end{array}$} & \multirow{2}{*}{$\begin{array}{c}\text { Senin } \\
5 \text { Oktober } 2020\end{array}$} & $08.30-10.00$ & $\begin{array}{l}\text { Mengajar Di SDI } 225 \\
\text { Bonto Masugi }\end{array}$ & Dusun Bonto Masugi & Peserta KKLP & $\begin{array}{l}\text { Pengetahuan siswa } \\
\text { semakin bertambah }\end{array}$ \\
\hline & & & $16.00-17.00$ & $\begin{array}{c}\text { Mengecat Tempat } \\
\text { Sampah }\end{array}$ & Dusun Bonto Masugi & Peserta KKLP & - \\
\hline & & \multirow[b]{2}{*}{$\begin{array}{c}\text { Selasa } \\
6 \text { Oktober } 2020\end{array}$} & $09.00-10.00$ & $\begin{array}{c}\text { Mengajar Di SD INP } \\
119 \text { Bontowa }\end{array}$ & $\begin{array}{l}\text { Dusun Camba } \\
\text { Lompoa }\end{array}$ & Peserta KKLP & $\begin{array}{l}\text { Pengetahuan siswa } \\
\text { semakin bertambah }\end{array}$ \\
\hline & & & $16.00-17.00$ & $\begin{array}{c}\text { Membuat Papan Nama } \\
\text { Kepala Dusun, Iman } \\
\text { Dusun, Iman Desa dan } \\
\text { RK }\end{array}$ & Dusun Bonto Masugi & Peserta KKLP & - \\
\hline & & \multirow{3}{*}{$\begin{array}{c}\text { Rabu } \\
7 \text { Oktober } 2020\end{array}$} & $07.00-07.30$ & Membersihkan Posko & Rumah Kepala Desa & Peserta KKLP & $\begin{array}{c}\text { Membuat Posko menjadi } \\
\text { Bersih }\end{array}$ \\
\hline & & & $09.00-10.00$ & $\begin{array}{l}\text { Mengajar Di SDN No } \\
263 \text { Bonto Baru }\end{array}$ & Dusun Bonto Baru & Peserta KKLP & $\begin{array}{l}\text { Pengetahuan siswa } \\
\text { semakin bertambah }\end{array}$ \\
\hline & & & $18.10-19.00$ & Mengajar TPA/TPQ & $\begin{array}{l}\text { Masjid Ar - Rahman } \\
\text { Al Mu'minim }\end{array}$ & Peserta KKLP & $\begin{array}{c}\text { para santri mengetahui } \\
\text { betapa pentingnya belajar } \\
\text { Al-Quran }\end{array}$ \\
\hline & & \multirow{2}{*}{$\begin{array}{c}\text { Kamis } \\
8 \text { Oktober } 2020\end{array}$} & $14.00-15.30$ & $\begin{array}{c}\text { Membuat Papan Nama } \\
\text { Kepala Dusun, Iman } \\
\text { Dusun, Iman Desa dan } \\
\text { RK }\end{array}$ & Dusun Bonto Masugi & Peserta KKLP & - \\
\hline & & & $18.10-19.00$ & Mengajar TPA/TPQ & $\begin{array}{l}\text { Masjid Ar - Rahman } \\
\text { Al Mu'minim }\end{array}$ & Peserta KKLP & $\begin{array}{c}\text { para santri mengetahui } \\
\text { betapa pentingnya belajar } \\
\text { Al-Quran }\end{array}$ \\
\hline & & \multirow{2}{*}{$\begin{array}{c}\text { Jum'at } \\
9 \text { Oktober } 2020\end{array}$} & $08.00-10.00$ & $\begin{array}{l}\text { Melakukan jum'at } \\
\text { bersih }\end{array}$ & - & Peserta KKLP & $\begin{array}{l}\text { membuat masjid terlihat } \\
\text { bersih dan nyaman untuk } \\
\text { dipakai beribadah }\end{array}$ \\
\hline & & & $09.00-10.00$ & $\begin{array}{c}\text { Mengajar Di SD INP } \\
119 \text { Bontowa }\end{array}$ & $\begin{array}{l}\text { Dusun Camba } \\
\text { Lompoa }\end{array}$ & Peserta KKLP & $\begin{array}{l}\text { Pengetahuan siswa } \\
\text { semakin bertambah }\end{array}$ \\
\hline & & \multirow[t]{2}{*}{$\begin{array}{c}\text { Sabtu } \\
10 \text { Oktober } 2020\end{array}$} & $09.00-10.00$ & $\begin{array}{l}\text { Mengajar Di SDN No } \\
263 \text { Bonto Baru }\end{array}$ & Dusun Bonto Baru & Peserta KKLP & $\begin{array}{l}\text { Pengetahuan siswa } \\
\text { semakin bertambah }\end{array}$ \\
\hline & & & - & Istirahat & Dusun Bonto Masugi & Peserta KKLP & - \\
\hline & & $\begin{array}{c}\text { Minggu } \\
11 \text { Oktober } 2020\end{array}$ & 08.00-09.00 & Melaksanakan Baksos & Dusun Bonto Baru & $\begin{array}{c}\text { Peserta KKLP } \\
\text { dan } \\
\text { Masyarakat }\end{array}$ & $\begin{array}{l}\text { Agar Dusun Bonro Baru } \\
\text { Menjadi Bersih }\end{array}$ \\
\hline & \multirow[t]{4}{*}{$\begin{array}{c}\mathrm{V} \\
\text { (Kelima) }\end{array}$} & \multirow{3}{*}{$\begin{array}{c}\text { Senin } \\
12 \text { Oktober } 2020\end{array}$} & $10.00-12.00$ & $\begin{array}{c}\text { Rapat Tim Penggerak } \\
\text { PKK }\end{array}$ & $\begin{array}{l}\text { Kantor Desa Balang } \\
\text { Baru }\end{array}$ & $\begin{array}{l}\text { Tim PKK } \\
\text { Kepala Desa } \\
\text { Staff Desa } \\
\text { Masyarakat } \\
\text { Peserta KKLP }\end{array}$ & - \\
\hline & & & $16.30-17.15$ & $\begin{array}{c}\text { Membuat Tempat } \\
\text { Sampah }\end{array}$ & Dusun Bonto Masugi & Peserta KKLP & - \\
\hline & & & $18.10-19.00$ & Mengajar TPA/TPQ & $\begin{array}{l}\text { Masjid Ar - Rahman } \\
\text { Al Mu'minim }\end{array}$ & Peserta KKLP & $\begin{array}{c}\text { para santri mengetahui } \\
\text { betapa pentingnya belajar } \\
\text { Al-Quran }\end{array}$ \\
\hline & & $\begin{array}{c}\text { Selasa } \\
13 \text { Oktober } 2020\end{array}$ & $14.00-16.00$ & $\begin{array}{l}\text { Mengecat Papan nama } \\
\text { Kepala Desa, Kepala } \\
\text { Dusun, Iman Dusun, } \\
\text { Iman Desa Dan RK }\end{array}$ & Dusun Bonto Masugi & Peserta KKLP & - \\
\hline
\end{tabular}




\begin{tabular}{|c|c|c|c|c|c|c|}
\hline & & $18.10-19.00$ & Mengajar TPA/TPQ & $\begin{array}{l}\text { Masjid Ar - Rahman } \\
\text { Al Mu'minim }\end{array}$ & Peserta KKLP & $\begin{array}{c}\text { para santri mengetahui } \\
\text { betapa pentingnya belajar } \\
\text { Al-Quran }\end{array}$ \\
\hline & \multirow{2}{*}{$\begin{array}{c}\text { Rabu } \\
14 \text { Oktober } 2020\end{array}$} & 09.00-10.00 & $\begin{array}{l}\text { Mengajar Di SDN No } \\
263 \text { Bonto Baru }\end{array}$ & Dusun Bonto Baru & Peserta KKLP & $\begin{array}{l}\text { Pengetahuan siswa } \\
\text { semakin bertambah }\end{array}$ \\
\hline & & $14.00-16.00$ & $\begin{array}{l}\text { Mengecat Papan nama } \\
\text { Kepala Desa, Kepala } \\
\text { Dusun, Iman Dusun, } \\
\text { Iman Desa Dan RK }\end{array}$ & Dusun Bonto Masugi & Peserta KKLP & - \\
\hline & \multirow{2}{*}{$\begin{array}{c}\text { Kamis } \\
15 \text { Oktober } 2020\end{array}$} & $08.30-10.00$ & $\begin{array}{l}\text { Mengajar Di SDI } 225 \\
\text { Bonto Masugi }\end{array}$ & Dusun Bonto Masugi & Peserta KKLP & $\begin{array}{l}\text { Pengetahuan siswa } \\
\text { semakin bertambah }\end{array}$ \\
\hline & & $18.10-19.00$ & Mengajar TPA/TPQ & $\begin{array}{l}\text { Masjid Ar - Rahman } \\
\text { Al Mu'minim }\end{array}$ & Peserta KKLP & $\begin{array}{c}\text { para santri mengetahui } \\
\text { betapa pentingnya belajar } \\
\text { Al-Quran }\end{array}$ \\
\hline & \multirow{3}{*}{$\begin{array}{c}\text { Jum'at } \\
16 \text { Oktober } 2020\end{array}$} & 08.00-10.00 & $\begin{array}{l}\text { Melakukan jum'at } \\
\text { bersih }\end{array}$ & - & Peserta KKLP & $\begin{array}{l}\text { membuat masjid terlihat } \\
\text { bersih dan nyaman untuk } \\
\text { dipakai beribadah }\end{array}$ \\
\hline & & $09.00-10.00$ & $\begin{array}{c}\text { Mengajar Di SD INP } \\
119 \text { Bontowa }\end{array}$ & $\begin{array}{l}\text { Dusun Camba } \\
\text { Lompoa }\end{array}$ & Peserta KKLP & $\begin{array}{l}\text { Pengetahuan siswa } \\
\text { semakin bertambah }\end{array}$ \\
\hline & & $16.00-17.16$ & $\begin{array}{c}\text { Pemasangan Papan } \\
\text { nama Kepala Dusun, } \\
\text { dan Kepala Dusun }\end{array}$ & $\begin{array}{l}\text { Dusun Bonto Masugi } \\
\text { Dusun Camba } \\
\text { Lompoa } \\
\text { Dusun Bonto Baru } \\
\text { Dusun Bonto Manai }\end{array}$ & Peserta KKLP & - \\
\hline & $\begin{array}{c}\text { Sabtu } \\
17 \text { Oktober } 2020\end{array}$ & - & Istirahat & Dusun Bonto Masugi & Peserta KKLP & - \\
\hline & \multirow{2}{*}{$\begin{array}{c}\text { Minggu } \\
18 \text { Oktober } 2020\end{array}$} & 08.00-09.00 & Melaksanakan Baksos & - & $\begin{array}{c}\text { Peserta KKLP } \\
\text { dan } \\
\text { Masyarakat }\end{array}$ & $\begin{array}{l}\text { Agar Dusun Bonro Baru } \\
\text { Menjadi Bersih }\end{array}$ \\
\hline & & $16.00-16.30$ & $\begin{array}{l}\text { Pemasangan Papan } \\
\text { Nama Iman Desa dan } \\
\text { Iman Desa }\end{array}$ & $\begin{array}{l}\text { Dusun Bonto Masugi } \\
\text { Dusun Bonto manai }\end{array}$ & Peserta KKLP & - \\
\hline \multirow[t]{7}{*}{$\begin{array}{c}\text { VI } \\
\text { (Keenam) }\end{array}$} & \multirow[t]{2}{*}{$\begin{array}{c}\text { Senin } \\
19 \text { Oktober } 2020\end{array}$} & $16.00-17.30$ & $\begin{array}{c}\text { Pemasangan Papan } \\
\text { nama Kepala Desa dan } \\
\text { RK }\end{array}$ & $\begin{array}{l}\text { Dusun Bonto Masugi } \\
\text { Dusun Camba } \\
\text { Lompoa } \\
\text { Dusun Bonto Baru } \\
\text { Dusun Bonto Manai }\end{array}$ & Peserta KKLP & - \\
\hline & & $18.10-19.00$ & Mengajar TPA/TPQ & $\begin{array}{l}\text { Masjid Ar - Rahman } \\
\text { Al Mu'minim }\end{array}$ & Peserta KKLP & $\begin{array}{c}\text { para santri mengetahui } \\
\text { betapa pentingnya belajar } \\
\text { Al-Quran }\end{array}$ \\
\hline & $\begin{array}{c}\text { Selasa } \\
20 \text { Oktober } 2020\end{array}$ & 08.00-09.00 & $\begin{array}{l}\text { Membeli bahan untuk } \\
\text { membuat papan nama } \\
\text { jalan dan tempat wisata }\end{array}$ & Dusun Bonto Masugi & Peserta KKLP & - \\
\hline & $\begin{array}{c}\text { Rabu } \\
21 \text { Oktober } 2020\end{array}$ & $10.00-11.30$ & $\begin{array}{l}\text { Pembuatan Papan nama } \\
\text { Jalan dan tempat wisata }\end{array}$ & Dusun Bonto Masugi & Peserta KKLP & - \\
\hline & $\begin{array}{c}\text { Kamis } \\
22 \text { Oktober } 2020\end{array}$ & $17.00-17.30$ & Packing/pindah posko & $\begin{array}{c}\text { Dusun bonto masugi } \\
\text { ke dusun camba } \\
\text { lompoa }\end{array}$ & Peserta KKLP & - \\
\hline & \multirow[b]{2}{*}{$\begin{array}{c}\text { Jumat } \\
23 \text { Oktober } 2020\end{array}$} & $08.00-10.00$ & $\begin{array}{l}\text { Melakukan jum'at } \\
\text { bersih }\end{array}$ & - & Peserta KKLP & $\begin{array}{l}\text { membuat masjid terlihat } \\
\text { bersih dan nyaman untuk } \\
\text { dipakai beribadah }\end{array}$ \\
\hline & & $13.00-16.25$ & $\begin{array}{l}\text { Ikut Serta dalam } \\
\text { kegiatan sosialisasi } \\
\text { Penyuluhan hukum }\end{array}$ & $\begin{array}{c}\text { Kantor Desa Balang } \\
\text { Baru }\end{array}$ & $\begin{array}{l}\text { Kepala Desa } \\
\text { Staff Desa } \\
\text { Masyarakat } \\
\text { Peserta KKLP }\end{array}$ & - \\
\hline
\end{tabular}




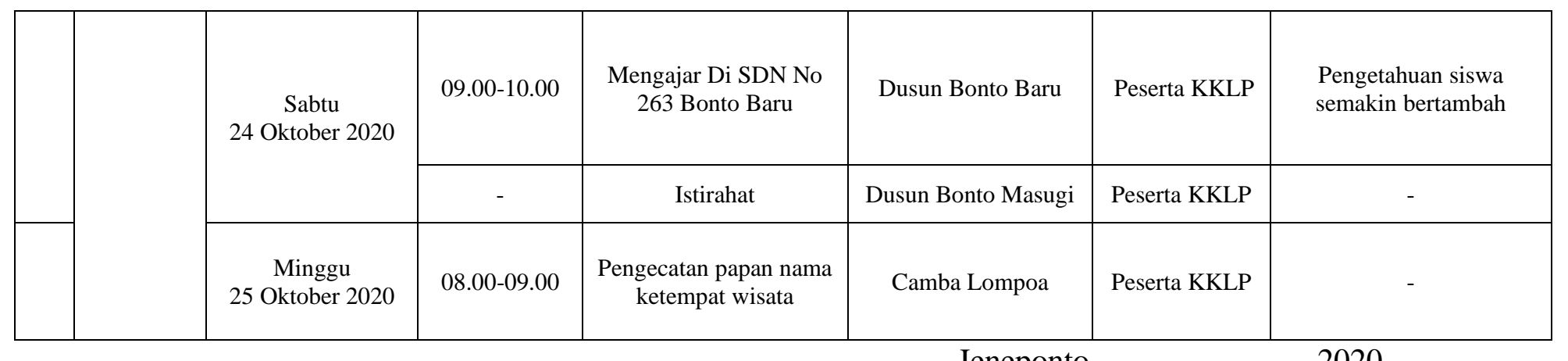

Jeneponto,

2020

Kepala Desa Balang Baru

Peserta KKLP

$\underline{\text { Darman Patta }}$

MUH. ISWAHYUDI SETIAWAN

Mengetahui,

Dosen Pembimbing

$\underline{\text { Rahim Sila, S.Pd, M.M }}$ 